\title{
МОДЕЛИ ПОВЕДЕНИЯ
}

Жежко И. В.

\section{ПОЛИТКОРРЕКТНОСТЬ В КОНТЕКСТЕ ПРОТЕСТНЫХ ДВИЖЕНИЙ}

Аннотация. В статье содержится полемика с книгой Леонида Ионина «Дивный, новый мир политкорректности» (2012). Ионин, осуществил попытку перейти от эмпирического и исторического описания к определению феномена, от примеров политической корректности - к анализу и объяснению его природы. Политкорректность определена автором следующим образом: «... это идеология современной массовой демократии, служащая, с одной сторонь, обоснованию внутренней и внешней политики западных государств и союзов, а с другой - подавлению инакомыслия и обеспечению идейного и цеенностного консенсуса». Проанализировано определение политкорректности и его обоснование автором; выявлены противоречия и ограниченность данного определения. Описывается сложный механизм возникновения и работы механизма политкорректности на примере жирондистских клубов и их роли во Франиузской революции. Приводятся примеры современной критики и оппозиции политкорректности в обществе массовой демократии. Предложено новое понимание феномена политкорректности, его этапов и составных частей в контексте протестных соичиальных движений.

Ключевые слова: либеральньй консенсус, протестное движение, меньиинства, Леонид Ионин, общественное мнение, массовая демократия, политическая корректность, Политология, Огюстен Кочен, идеология.

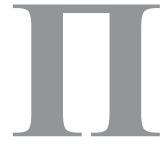
олиткорректность пышно расцвела в сегодняшней России при финансовой поддержке многочисленных грантов и средств массовой информации. Более того, политкорректное поведение не так уж ново в России, оно было весьма характерно для позднего, брежневского периода социализма, эпохи комфортного застоя, в академической среде, когда ни от кого из нас не требовалось верить в коммунистическую идеологию, достаточно было не бросать ей публичный вызов в печати, в диссертациях и устных выступлениях. Современный российский политкоррект- ный дискурс включает многие темы, характерные для аналогичного дискурса Америки и Европы: отношение к иммигрантам, равноправие полов, этническая и расовая политика и т.д. Большинство публикаций на эти темы носит описательный или публицистический характер. Недавно изданная книга Леонида Ионина «Политкорректность: дивный новый мир» ${ }^{1}$ выгодно отличается от других книг на эту тему, издаваемых в России и на Западе,

\footnotetext{
${ }^{1}$ Ионин Л.Г. Политкорректность: дивный новый мир. М.: Ад Маргинем, 2012.
} 
в том числе, в Америке. Она написана в теоретическом ключе и в этом ее отличительное достоинство, хотя и в ней достаточно много сочных, журналистских примеров и субъективных оценок.

\section{От описания политкорректности к ее анализу}

Судя по тому, что Ионин ссылается в своей книге, в основном, на западные источники, его книга является первой академической работой на данную тему на русском языке и в этом качестве уже интересна. Автор заслуживает отдельной похвалы за интеллектуальную смелость, т.к. эта тема реально взрывоопасна в академическом мире в России и за рубежом. Президент самого престижного в мире университета, Harvard University, Ларри Саммерс был вынужден покинуть свой пост за отдельное неполиткорректное высказывание в 2006 году를. Это один из наиболее известных, но далеко не единственный случай расправы за высказывание в недавней истории Америки.

Ионин предлагает свою версию определения политкорректности, генеалогии и механизма ее работы. Основные теоретические построения, вместе с определением феномена, уже были сформулированы автором в его предыдущей работе «Апдейт консерватизма»² и перекочевали в новую книгу практически без изменений. В этих двух книгах Ионин, осуществил попытку перейти от эмпирического и исторического описания к определению феномена, от примеров вопиющей политической корректности - канализу и объяснению его природы.

\footnotetext{
${ }^{1}$ Why Larry Summers lost the presidency of Harvard [online]. Date of access 01.03.2013. URL: <http://mathbabe. org/2012/03/11/why-larry-summers-lost-the-presidency-ofharvard/>.

${ }^{2}$ Ионин Л.Г. Апдейт консерватизма. М.: Изд. Дом Гос. ун-та - Высшая школа экономики, 2010.
}

Прежде, чем перейти к анализу авторского определения, необходимо сделать два общих методологических замечания. Не отрицая необходимости определения политкорректности как такового в теории этого феномена, я, тем ни менее, считаю неприемлемым начинать академический текст с определения, оставляя тем самым за пределами книги, как автор пришел к этому определению. Такое начало вполне возможно для публичных лекций, но не для научной работы. Я также нахожу непродуктивным строить такое определение как обобщение отнологических характеристик этого феномена, как это делает Ионин. Я намереваюсь показать дальше, что такое определение почти неизбежно становится противоречивым и поверхностно отражает суть явления, хотя при этом создается иллюзия теоретического объяснения. Более эффективным подходом я нахожу конструирование (выведение) понятия политкорректности на основе анализа истории и функций этого феномена, а также различных дискурсов и концепций. Примером такого типа теоретической работы может служить недавняя книга В. Розина о социальных институтах ${ }^{3}$. Учитывая, что автор определил жанр своей работы в аннотации как эссе, она скорее всего тяготеет к жанру публичной лекции и возможно не претендует на комплексное построение понятия «политкорректность», но и в этом качестве содержит ряд важных положений, заслуживающих обсуждения.

Книга Ионина интересна как самый первый шаг в направлении построения понятия, так как она знакомит нас с некоторыми онтологическими характеристиками объекта изучения, а также с некоторыми подходами и теориями в области изучения политкорректности в западной психологии и социологии.

\footnotetext{
${ }^{3}$ Розин В.М. Становление и особенности социальных институтов: Культурно-исторический и методологический анализ. М: Либриком, 2013. С. 11 и далее.
} 


\section{Неуловимый феномен политкорректности}

Композиция книги построена следующим образом: определение, практические и теоретические иллюстрации и пояснения к сути определяемого явления; взятые из нескольких источников, и заключение, в котором автор повторяет исходное определение и акцентирует значимость проблемы для западной цивилизации.

Литература на тему политкорректности уже весьма обширна и в ней существует много разных определений этого феномена. Часть из них Ионин цитирует в предыдущей книге ${ }^{1}$. Как автор замечает в предисловии, «США в области политкорректности... идут впереди всего мира» ${ }^{2}$, поэтому далее в своих замечаниях я буду опираться, в основном, на американский опыт и публикации. Многочисленные несовпадающие определения политкорректности напоминают классическую притчу о слепцах и слоне: определения характеризуют разные элементы этого сложного явления, не создавая однако целостной картины. Кроме того, как справедливо замечает автор: «Изучение и критика политкорректности затруднены тем, что она существует в виде набора никогда и нигде полностью и однозначно не выраженных и не опубликованных нормативных требований или же достаточно распльввачатых пожеланий относительно публичного и частного поведения...» . Дополнительная сложность изучения это феномена, добавлю от себя, состоит в том, что нормативные требования - это только его наиболее видимая часть, надводная верхушка айзберга, все остальное скрыто от глаз публики и требует специаль-

\footnotetext{
${ }^{1}$ Ионин Л. Г. Апдейт консерватизма. М.: Изд. Дом Гос. ун-та - Высшая школа экономики, 2010. С. 37.

${ }^{2}$ Ионин Л. Г. Политкорректность... 2012. С. 8.

${ }^{3}$ Ионин Л. Г. Политкорректность... 2012. С. 42.
}

ных исследований. Более того, как только какое-либо из направлений политкорректности институционализируется и легитимизируется (получает нормативное описание), оно, тем самым, превращается в один из нормативных институтов (цензурный комитет, экспертизу, лицензионный комитет, «министерство правды», и т.д.) и перестает быть самим собой, а именно частью публичного дискурса, одним из сегментов («формой существования» ${ }^{4}$, как говорит автор) общественного мнения.

Политкорректность определена Иониным следующим образом: «... это идеология современной массовой демократии, служащуая, с одной стороны, обоснованию внутренней и внешней политики западных государств и союзов, а с другой - подавлению инакомьслия и обеспечению идейного и иеенностного консенсуса» ${ }^{5}$.

В этом определении всё, или почти всё, вызывает возражение, а главное, что по мере раскрытия содержания феномена, автор входит в конфликт со своим собственным определением. Хочу отметить, что цель этой заметки не ответить на вопрос, какое из известных определений правильнее, а показать, что попытка Ионина описать и объяснить феномен политкорректности, заслуживающая наше искреннее уважение, оказалась, в конечном счете, не вполне адекватна сложности описываемого им явления, хотя и, безусловно, указывает на некоторые важные его проявления и компоненты.

\section{Идеология политкорректности}

Начнем, как и полагается, с начала определения: политкорректность — «... это идеология...». Это утверждение только на первый взгляд кажется очевидным, почти

\footnotetext{
${ }^{4}$ Ионин Л. Г. Политкорректность... 2012. С. 47.

${ }^{5}$ Ионин Л.Г. Политкорректность... 2012. С. 8, 104.
} 
тавтологическим, так как далее Ионин показывает, что политкорректность - не просто идеология, а идеология со встроенными механизмами. Это все равно, что назвать автомобиль горючим, в который встроен мотор, тормоза и т. Д. Причём у автора внутрь политкорректности оказываются «вмонтированными» не один, а сразу несколько механизмов: «спираль молчания», формирование повестки дня и т. д. (см. главу «Как работает политкорректность» ${ }^{1}$. Не только название, но и все содержание этои главы указывает на то, что автор трактует понятие политкорректности как сложный социальный механизм, иначе говоря машину, частью которого является идеология. Один из механизмов отвечает за выработку системы ценностей и определенного политкорректного языка, а с ним и картины мира (иначе говоря «сконструированной реальности», «повестки дня»). Другой механизм обеспечивает распространение и навязывание ее обществу (через школы, университеты, церкви, медиа и т.д.), т. е. собственно формирование общественного мнения или консенсуса по тому или иному вопросу. Третий - отвечает за подавление критики политкорректных идеологем: «... в идеологию политкорректности оказался вмонтированным своеобразный теоретический механизм, благодаря которому не только заранее отвергается любая критика, но и сам критик оказывается обвиненным в самых тяжких грехах...»². Автор вслед за современными философами называет этот механизм «теоретическим», однако тут же приводит примеры физической расправы за инакомыслие: «в 30-е годы прошлого века именно этот механизм... стал одним из инструментов легитимации террора протов идеологических девиантов

\footnotetext{
${ }^{1}$ Ионин Л. Г. Политкорректность... 2012. С. 64-80.

${ }^{2}$ Ионин Л. Г. Политкорректность... 2012. С. 34.
}

в СССР, а позже... инструментом идеологического террора как такового»³. Механизм подавления не то что критики, а даже случайного нарушения языковых и смысловых конвенций политкорректности в наши дни, как мы знаем, самый что ни на есть практический: от гильотины в XVIII до потери работы по профессии в XXI веке.

Автор интуитивно ощущает, что феномен политкорректности не сводится к одной идеологии, это видно из его многочисленных попыток говорить об «идеологии политкорректности» ${ }^{4}$, т.е. приводит к тавтологии: «идеология идеологии». Если же он этим словоупотреблением противопоставляет идеологию политкорректности другим идеологиям, то из книги остается неясно, каким именно. В частности, как по его мнению идеология политкорректности отличается от самой близкой к ней либеральной идеологии? На этот вопрос в книге нет ответа. Ионин также приводит примеры использовании полткорректной идеологии в борьбе за власть и влияние, однако останавливается на полпути и не делает следуещего шага в конструировании этого понятия, а именно рассмотрения его в контексте протестной (политической) деятельности. Одно из возможных объяснений этому состоит в том, что автор привлекает, в основном социальнопсихологические и культурологические теории для объяснения феномена политкорректности, делая ударение на корректности, и забывая о второй компоненте этого составного понятия - политическая

Идеология сама по себе не может быть корректной или некорректной, она становится таковой только в отнесении к определенной системе ценностей и только внутри уже выстроенного механизма контроля над общественным

\footnotetext{
${ }^{3}$ Ионин Л. Г. Политкорректность... 2012. С. 34.

${ }^{4}$ Ионин Л. Г. Политкорректность... 2012. С. 43, 71, 80 и т.д.
} 
мнением как одного из инструментов власти. Вторичность собственно идеологии политкорректности по отношению к объемлещему ее механизму контроля общественного сознания доказывается тем фактом, что сам механизм остается практически неизменным уже почти 300 лет, в то время, как он «заправлялся» разными идеологиями (как разными видами топлива, продолжая аналогию с автомобилем) в разные периоды его существования, причем идеологиями не только либерального направления. Ядро и формулировка одной и той же политкорректной ценности могут также меняться со временем ${ }^{1}$. Еще вчера идеология потепления планеты (global warming) была у всех политиков на устах, сегодня она поменялаась на «изменение климата». В соответствии с Оруэловским механизмом манипуляции общественным сознанием последняя редакция политической идеологемы является единственно правильной в каждый данный момент и отменяет все предшествующие формулировки.

\section{Когда возник феномен политкорректности?}

Политкорректность - «... это идеология современной массовой демократии...». Во этой части определения содержатся два тезиса: а) политкорректность есть плоть от плоти массовой демократии как социальной системы, б) она возникла вместе с ней. Оба тезиса вызывают большой скептицизм. Доказывая первый тезис, Ионин демонстрирует, что политкорректность есть результат тотального применения принципа равенства в его наиболее абстрактном понимании в разных сферах общественной жизни совре-

1 В этом отношении крайне интересна глава «Семантические и лексические изменения» в книге Hughes Geoffrey. Political correctness: A history of semantics and culture. Chichester (UK): Wiley-Blackwell, 2010. P. 26, etc. менной массовой демократии (глава «Рождение политкорректности из духа равенства»²). Между тем, высказывание Токвиля ${ }^{3}$, которым Ионин иллюстрирует этот тезис, относится к первой трети XIX века, когда американская демократия еще находилась в стадии становления» следовательно этот механизм политкорректоности уже сложился и функционировал в американском обществе. Более того, существуют работы, утверждающие, что основные механизмы политкорректного поведения возникли еще до того, как массовая демократия оформилась как социальная система. Некоторые исследователи ${ }^{4}$ датируют рождение политкорректности эпохой Реформации в Англии (XVI век), и показывают, что этот механизм дошел почти неизменным до наших дней. Французкие историки впервые описали механизм политкорректности в главных чертах, изучая опыт философских обществ, сложившихся в эпоху, предшествующую Французской революции; сама революция, по их мнению, явилась первой манифестацией и социальным экспериментом по последовательному проведению политкорректности в жизнь. Я позволю себе краткий исторический экскурс, чтобы показать насколько сегодняшняя ситуация с политкорректностью напоминает то, что происходило в годы, предшествующие Французской революции.

\section{Общества жирондистов как пример формирования механизма политкорректности}

Зарождение политической корректности во Франции и первый эксперимент по ее практическому воплощению в жизнь описан

\footnotetext{
${ }^{2}$ Ионин Л. Г. Политкорректность... 2012. С. 21-29.

${ }^{3}$ Ионин Л. Г. Политкорректность... 2012. С. 65-66.

${ }^{4}$ Hughes G. Political correctness: A history of semantics and culture. Chichester (UK): Wiley-Blackwell, 2010. П. 232 , etc.
} 
французским историком Огюстеном Кошеном ${ }^{1}$ (автор не пользовался этим термином, сам термин возник только в XX веке). Можно спорить с Кошеном по поводу причин Французской революции, но трудно опровергнуть результаты сделанного им детального анализа роли, которую сыграли провинциальные клубы и философские общества в ее подготовке. Это, по-видимому, самое первое исследование, показывающее на примере обществ жирондистов, как складывался и работал механизм полититкорректности и как он обеспечил приход носителей этой идеологии к власти. В этом смысле французы действительно указали дорогу человечеству к будущему, такому, в котором власть будет контролироваться не только и не столько демократически избранными лидерами, сколько институтом общественного мнения, и, в частности, теми, как сказали бы сейчас, политтехнологами, кто научился им манипулировать.

Вожди Французской революции, не будучи сами философами и даже преуспевающими в какой-либо профессии, встали во главе движения, а затем и государства, вооружившись идеологемами Просвещения. Кошен задает вопрос, как могла нация, признанный интеллектуальный и моральный лидер западной цивилизации, превратиться в толпу, которая меньше чем за два года довела страну до голода, сотворив демографическую яму, от которой потом восстанавливалась в течение целого поколения ${ }^{2}$ ? Историк доказал, что событие такого масштаба не могло быть результатом одномоментного заговора, а готовилось в течение нескольких лет.

Новая социальная система была выведена в «пробирках» французских философских обществ, где сложился определенный способ

\footnotetext{
${ }^{1}$ Cochin A. Organizing the Revolution. Rockford (IL): Chronicles press, 2007.

${ }^{2}$ Cochin A. Organizing... 2007. P. 68-70.
}

(механика) достижения полного единодушия (консенсуса). Затем эта модель была опробована на целой нации. Люди собирались в этих обществах для свободного обмена идей в полном соответствии с принципами демократии a la Жан Жак Руссо. Со временем внутри обществ стали совершаться совершенно одинаковые превращения. Большинство членов стало терять интерес к собраниям, где по многу часов и с равным вниманием дискутировались продуманные мысли и вздорные идеи. Люди, у которых были дела, таланты и влечения к другим занятиям, постепенно покидали общества. Те, кто оставались, часто не имели других занятий, не были довольны своими профессиями, зато имели политические амбиции. Вот так получилось, что без всякого насилия, автоматически произошел отбор, чистка обществ от наиболее компетентных и приспособленных к реальной жизни людей. Заслуга Кошена состоит в том, что он первый детально описал социальную динамику отдельного общества (в современной теории - малой группы), социологический механизм, построенный на последовательном проведении абстрактного принципа свободы мнений. Этот механизм обеспечивал чистку обществ от людей, чьи мнения были отличны от остальных, и тем самым создавал полное единодушие внутри каждого отдельного общества. Можно возразить Кошену, что бывшие члены обществ могли бы не поддерживать решения, принятые в них, в частности, с те, которые потом определили трагическую судьбу Франции. Теоретически они имели такой шанс, однако теперь каждый из них был в одиночестве, теперь особое и частное мнение протовостояло мнению большинства, и как частное мнение его надо отстаивать в бесконечных дискуссиях в тех же обществах. От каждого «дезертира», или диссидента, требовалось особое мужество восстать против «общественного консенсуса». Таким образом, Кошен задолго до немецкой исследователь- 
ницы Э. Ноэль-Норман обнаружил «спираль молчания». Он также открыл и описал второй закон динамики таких обществ (групп), fait accompli $^{1}$ [4, p. 83]: если что-то однажды сделано определенным образом, черезвычайно трудно этп изменить, отказаться от этого якобы общепринятого решения без публичного его обсуждения. Законы, описанные Кошеном, теперь широко известны в современной теории динамики групп.

Накануне Французской революции существовало несколько центров, «кующих» идеологию, только Якобинское общество насчитывало порядка 1900 дочек в 1794². Можно представить, каким прессом для мнения образованных людей они являлись. Философские общества «переваривали» общественное сознание, формируя то, что сейчас называют либеральным консенсусом. Во время правления якобинцев, многочисленные местные философские общества Франции соорганизовались по принципу матрешки: на национальном уровне общество было просто повторением местного общества только в увеличенном виде. Сеть таких обществ координировала свои решения и действия в масштабах страны. Только теперь свобода дискуссий на национальном уровне была дополнена ещё одной свободой - свободой действия, которая во вновь созданной демократии сводилась к равному избирательному праву и праву избавляться от несогласных. Машина освобождения от деятельных и практически мыслящих людей на национальном уровне завертелась гораздо быстрее, чем на местном, так что процесс чистки инакомыслящих (создание консенсуса), ускоренный массовым террором, завершился в очень короткие сроки. Кошен показал на этом примере, что явление политкорректности не есть продукт массовой демократии в ее те-

\footnotetext{
${ }^{1}$ Fait accompli (fr.) - дело сделано.- Прим. авт.

${ }^{2}$ Cochin A. Organizing... 2007. P. 80.
}

перешнем виде, а есть результат индоктринации общества абстрактными принципами демократии (тут Ионин находится в полном согласии с Кошеном) вкупе с захватом власти в полном соответствии с демократическими процедурами.

Кошен также обнаружил, что групповой гипноз «единственно правильной» системы ценностей и построенного на ней социального эксперимента не может длиться бесконечно, а только до той поры, когда сохранившие здравомыслие люди не осозна́ют его пагубность для общества (при условии, что их число приближается к критической массе). Мы вернемся к этой утешительной мысли, но уже на примере сегодняшнего опыта политкорректности.

\section{Политкорректность - норма или болезнь демократии?}

«Политкорректность ... это идеология современной массовой демократии...». Если понимать эту фразу определения так, что политкорректность есть идеология самой демократии, то многочисленные примеры из книги Ионина, не говоря о других публикациях, однозначно свидетельствуют об обратном. Идеология политкорректности открыто воюет с демократией и ее ценностями, находясь при этом под ее надежной защитой. Кошен, а также многие современные исследователями, убедительно доказывают, что политкорректность разрушает основные ценности западной цивилизации, прежде всего, свободу слова, свободу вероисповедания, свободный суд, свободу личной неприкосновенности и частной жизни. Здесь Здесь уместно привести цитату французского историка Ипполита Тена ${ }^{3}$ в той

\footnotetext{
${ }^{3}$ Ипполит Тен (1828-1893) — автор монументальной работы в шести томах «Les Origines de la France Contemporaine» («The Origins of Contemporary France. 1962).
} 
главе его знаменитой книги о Французской революции, где он пишет о законах, принятых конституционной ассамблеей в 1789 году: «... теоретическая свобода (в этих законах И.Ж) разрушает реальную свободу... и существующие мнения, правосудие убивает без следствия и суда. Mbl видим, что случилось немыслимое: деспотизм свободы, фанатизм разума... Гуманизм, который убивает, есть родная сестра свободы, которая сажает в тюрьму, братства, которое шпионит, разума, который страдает нетерпимостью, и все они соединяются вместе и воплощуют этот странный сочииальный феномен, называемый Якобинством» ${ }^{1}$.

Идем далее в Ионинском определении: «политкорректность...- это идеология... служащуая... обоснованию внутренней и внешней политики западных государств и союзов...».

Эта часть определения практически ничего не добавляет к содержанию феномена политкорректности и его специфике, т.к. практически любая идеология может служить обоснованием внешней и внутренней политики. Марксистская идеология мировой революции в этом смысле ничем не отличается, например, от идеологии насаждения демократии во всем мире. Скорее всего, эта фраза понадобилась автору, чтобы описать последствия экспорта демократии и «цветных революций», столь же разрушительные, сколь и экспорт социалистической революции был в ХХ веке. В этой части определения чувствуется влияние на автора старой школы советской социологии, в которой одним из правил политкорректности было разрешение на цитирование и пересказ теорий западных авторов при условии уравновешивания их мнений «критикой буржуазной социологии с позиций марксизма».

${ }^{1}$ Taine H. The Origins of Contemporary France. Glouster, Mass: Henry Holt \& CO, 1962. P. 177.

\section{Политкорректность в борьбе с инакомыслием}

И, наконец, последний и, по мнению автора, самый специфический для описываемого явления фрагмент определения: политкорректность - «это идеология... служашчая... подавлению инакомыслия и обеспечению идейного и цуенностного консенсуса».

Именно этой функции политкорректности, в основном, и посвящена книга Ионина ${ }^{2}$. Автор указывает на угрозу всей западной цивилизации (в том числе России), которую несет с собой политкорректность как социальный механизм навязывания власти меньшинств современным обществам. Соглашаясь с автором в оценке меры опасности современной политкорректности, нельзя не удивиться, однако, что он нигде в своей книге не указал на силы, противодействующие этой угрозе в демократическом обществе. Одно из возможных объяснений этому я предложу далее.

В этой, самой содержательной, на мой взгляд, части определения политкорректности кроется вместе с тем некоторый подвох в авторском понимании этого феномена. В имеющейся литературе существуют, как минимум, два разных понимания роли и места политкорректности в современном общественном мнении.

Одно направление, Ионин, судя по его тексту, принадлежит к нему, считает, что идеология политкорректности уже обеспечила «либеральный консенсус» пусть и ценою удержания остальной части общества в состоянии «молчаливого большинства». Автор предваряет свою книгу следующей фразой: «Работающий повсюду в демократическом мире механизм победы иумных меньшинств над молчаливым большинством детально разбирается ниже... А сейчас несколько примеров

\footnotetext{
${ }^{2}$ Ионин Л. Г. Политкорректность... 2012. С. 105.
} 
из мира победивщей политкорректности (выделено мной - И.Ж)»1.

Другое направление понимает действия идеологов политкорректности как агрессивное инакомыслие, как борьбу меньшинств не только за признание и гражданское равенство, но и за власть и привилегии в обществе, которое в целом не разделяет их предельно абстрагированные ценности, как борьбу небольшой, но активной группы, а точнее альянса групп, с большинством. Это большинство может быть и молчит до определенной поры до времени, но время от времени находит способы выразить свое несогласие.

Многочисленные опросы и результаты голосований по отдельным пунктам либеральной повестки убедительно показывают, что ее сторонники находятся в меньшинстве в американском обществе, хотя соотношение голосов за и против варьируется в зависимости от пунктов повестки и социальной ситуации. Вот почему идеология политкорректности сама есть, фактически, инакомыслие, вполне допускаемое демократией, но лишь до того момента, когда оно начинает говорить и действовать якобы от лица большинства. Движение политкорректности пытается представить себя в качестве mainstream opinion с помощью ассимилированных ими институтов, подменяет процесс формирования общественного мнения его суррогатом - молчаливым большинством, манипулирует процессом его формирования. Сторонники второго направления считают, что США и Европа может быть все еще живут в эпоху триумфа публичной политкорректности, однако ее власть над общественным мнением уже прошла верхнюю точку, за которой виден крутой спуск... Очнувшись от гипноза, общества западной цивилизации начали то, что называется reality check, т.е подвергать сомнению все реалии и ценности современной

\footnotetext{
${ }^{1}$ Ионин Л.Г. Политкорректность... 2012. С. 7.
}

парадигмы политкорректности. Различные группы активно занялись ревизией всех областей, куда она проникла: пересматриваются учебники и школьные программы, медицинские правила и процедуры, создаются новые дискуссионные форумы и т.д. Выкорчевывание политкорректности в ее наиболее разрушительных для демократических обществ формах может занять много времени,- может быть сравнимое с периодом ее воцарения, но «процесс пошел». Тут уместно вспомнить, к какому выводу пришел Кошен, анализируя ход Французской революции: «... хотя устрашенная страна терпела тиранию «маленьких людей» из философских обществ какое-то время, ее правление не могло быть долгим. «Большие люди» были слишком полны жизни, чтобы подчиниться или быть совращенными инеричиеи. Клубы, в конце концов, не были самой нацией. Нация... начала распрямляться после Термидора... здравый смысл постепенно одержал победу в общественном сознании. Франция задышала опять, очнувшись от ночного кошмара»².

\section{Бунт молчаливого болышинства}

Политкорректность как феномен подавления мнения большинства меньшинством уже описан в главных чертах во множестве работ, объяснен, а значит стал менее опасен. «Сеанс публичного разоблачения магии» уже состоялся. Все меньше и меньше страха испытывают люди, нарушающие табу политкорректности. Вот только три недавние истории из американской жизни.

Владелец сети ресторанов Chick-fil-A публично заявил о поддержке брака между мужчиной и женщиной как основы семьи и пожертвовал крупную сумму на это движение. Активисты политкорректности осудили этот

${ }^{2}$ Cochin A. Organizing... 2007. P. 100. 
поступок, направленный, как они считают, против гомосексуалистов, и объявили бойкот $\mathrm{v}$ прессе заведениям этого ресторана по всей Америке. Если бы страна жила в мире победившей политкорректности, этот бизнес должен был раззориться, однако тысячи людей выстроились в очередь к ресторанам Chick-fil-A, демонстрируя свою моральную поддержку1

Не менее знаменателен другой пример. Когда администрация президента Обамы издала указ о том, что католическая церковь и ее организации должны оплачивать своим служащим-женщинам медицинские услуги, связанные с абортом, церковь восстала против этого закона, усмотрев в нем наступление на один из столпов ее религии, и, следовательно, на свободу религии в целом². Значительная часть общества и других конфессий открыто поддержала лидеров католической церкви.

Президент Обама и демократическая партия в своей предвыборной платформе выступили в поддержку права геев и лесбиянок на легальный брак. Еще недавно эти заявления были бы последней точкой в затянувшемся споpe. Однако более половины из 50 штатов США приняли в последние годы конституционную поправку (или специальный закон) о том, что брак - это союз между мужчиной и женщиной ${ }^{3}$. Взятые вместе эти и другие примеры

\footnotetext{
${ }^{1}$ Leon E. de Put down that Chick-fil-A! [online] Date of access 01.03.2013. URL: http://www.huffingtonpost.com/ erwin-de-leon/put-down-that-chick-fil-a_b_1906352.html

${ }^{2}$ O'Brien N. F. Federal lawsuits by Catholic dioceses, groups seek to stop HHS mandate [online]. Date of access 01.03.2013. URL: http://www.catholicnews.com/data/ stories/cns/1202080.htm

${ }^{3}$ List of U.S. state constitutional amendments banning samesex unions by type // Wikipedia [online]. Date of access 01.03.2013. URL: http://en.wikipedia.org/wiki/List_of_U.S. state_constitutional_amendments_banning_same-sex_unions_ by_type>. При этом в некоторых из этих штатов одновременно легализована регистрация гражданских однополых союзов, однако без той системы поддержки, которыми государство обеспечивают институт семьи и брака.
}

показывают, что вряд ли сегодняшнее состояние общественного мнения в Америке по этим пунктам политкорректности можно назвать миром победившей политкорректности, как это считает Ионин.

Историю произошедшего сдвига в общественном сознании можно также проследить по названиям книг, изданных в последнее время. Большинство публикаций разоблачает внутреннюю противоречивость и лицемерие идеологии и практики либеральной политкорректности, демонстрирует ее губительное воздействие на основы и стабильность западной цивилизации ${ }^{4}$.

Даже, если принять тезис, что политкорректность есть плоть от плоти массовой демократии, ее органический порок, все равно неочевидно, что демократии не смогут преодолеть эту «болезнь» и выработать к ней противоядие. Кроме того, не все массовые демократии равны между собой. Американская демократия и в этом отношении «впереди всех» и учится на опыте европейских. Книги Ионина, к сожалению, представляют только одну сторону в споре о политкорректности, а именно, сторону

\footnotetext{
${ }^{4}$ Debating P.C.: The controversy over political correctness on college campuses / Ed. by P. Berman. New York, 1992; Political correctness: For and against / M. Friedman and J. Narveson. Lanham, Md.: Rowman \& Littlefield, 1995; Unprotected: A campus psychiatrist reveals how political correctness in her profession endangers every student by anonymous, M.D. New York: Sentinel, 2006; Chin J. The AIDS pandemic: The collision of epidemiology with political correctness. Oxford; Seattle: Radcliffe, 2007; Kimball R. The rape of the masters: How political correctness sabotages art. San Francisco: Encounter Books, 2004; Feaman P. The next nightmare: How political correctness will destroy America. Nashville, Dunham Book, 2012; McGowan W. Coloring the news: How political correctness has corrupted American journalism. San Francisco: Encounter Books, 2002; Satel S. PC, M.D.: How political correctness is corrupting medicine. New York: Basic Books, 2000; Schwartz H. S. Society, against itself: Political correctness and organizational self-destruction. London: Karnas Books Ltd, 2010; Walker R. Without firing a shot: The death of American liberty through political correctness. Roncore, 2010.
} 
левых интеллектуалов ${ }^{1}$. Левые интеллектуалы (по американской терминологии - либералы, или прогрессисты), составляющие большинство во многих университетах, своего рода нео-жирондистских обществах, может быть, и достигли между собой консенсуса по поводу заката западной демократии, однако, пребывая в собственном параллельном мире, они не заметили, что земля потихоньку уходит из-под их ног. Новость о смерти западной цивилизации может оказаться слегка преждевременной: подобно героям научно-фантастических фильмов и романов, хранители ее ценностей восстали, чтобы вернуть свои земли.

\section{Концепция политкорректности}

Вопрос о генеалогии и теории политкорректности является одним из центральных в книге Ионина, и, по-видимому, его основным вкладом в исследование этого феномена. Однако теорию или, как пишет автор, методологию политической корректности можно понимать в двух смыслах. В первом, как теоретическое о (бо) снование ее идеологии ${ }^{2}$, и во втором - как теорию социального феномена политкорректности в целом. В первом смысле теория понимается Иониным как группа источников, откуда политкорректность черпает смыслы, ценности и способы их обоснования (justification). "Действительно ли у практики политкорректности сегодня отсутствует теоретико-методологический фундамент? Нет, не отсутствует, он имеется, и в этой роли выступает постмодерн».3. В соответствующей главе автор развернуто обосно-

\footnotetext{
${ }^{1}$ Справедливости ради надо сказать, что Ионин хорошо осведомлен об оппозиции политкорректности. См.: Ионин Л. Конец мультикультурной эпохи // Русский журнал. 06.12.2010 [online]. Дата обращения 04.03.2013. URL: <http:/www.russ.ru/pushkin/Konec-mul-tikul-turnojepohi>.

${ }^{2}$ Ионин Л. Г. Политкорректность... 2012. С. 42 и далее.

${ }^{3}$ Ионин Л. Г. Политкорректность... 2012. С. 43.
}

вывает, что марксистская идеология и базирующиеся на ней теории в эпоху постмодернизма могут считаться такими источниками. С этими утверждением автора можно было бы согласиться, однако теоретико-методологический и идеологический фундамент политкорректности не может служить теоретическим объяснением социального феномена как целого. Более того, как считают многие исследователи, феномен политкорректности практически индифферентен к идеологии, которую он использует в своих аргументах в диалоге с обществом, однако при этом он всегда сохраняет вектор на разрушение ценностей большинства.

Что же касается теории политкорректности в более широком смысле - как общественного движения или особой социальной машины, то началом этого направления следует считать работы историков французской школы политических наук: Тена, Острогорского ${ }^{4}$, Токвиля и Кошена. Ионину и цитируемым им ученым удалось продвинуться несколько дальше своих предшественников и набросать первый эскиз, а точнее четыре узла этой социальной машины. Некоторые из них прописаны довольно подробно в книге Ионина, другие просто упомянуты ${ }^{5}$. В данной заметке не место приводить эти узлы в систему, однако необходимо заметить, что фазы работы механизма политкорректности практически повторяют основные этапы развития типичного общественного (протестного) движения ${ }^{6}$.

\footnotetext{
${ }^{4}$ Марк Острогорский (1854-1919), родом из Белоруссии, некоторое время жил во Франции и писал по-французски. ${ }^{5}$ Ионин Л. Г. Политкорректность... 2012. С. 47; 70-80.

${ }^{6}$ Основные этапы социального движения сформулированы в нескольких работах, в частности: Moyer B. Doing democracy: The MAP Model for organizing social movements. Gabriola Island (BC): New Society publishers, 2001. В этой книге описывается динамика управляемого общественного протестного движения, которая в том числе включает четыре этапа, кратко обозначенные Иониным.
} 
Любое общественное движение (феминизм, черное движение, антиглобализм, ЛГБТ и т.д.) в активной фазе формулирует и время от времени пересматривает свои ценности и идеологемы, маркирует их как корректные и некорректные на текущем этапе и тем самым вносит свой вклад в общую копилку политкорректного языка. Иначе говоря, политкорректность включает конгломерат промаркированных ценностей активных протестных движений и развивается по той же траектории, что и сами движения. В кратком изложении каждое отдельное движение проходит через следующие фазы:

- порождение идеологем политкорректности и повесток дня (agenda): фабрики мысли (think tanks), философские школы и кружки («правящие» и «ценностные» элиты и их организации);

- формирование общественного мнения, или навязывание идеологем большинству как основной механизм политкорректности. Первенство в описании этого механизма на примере масонских лож и политических партий принадлежит Острогорскому. Он, механизм, существенно развился в эпоху демократии, когда партиям и движениям понадобилось обеспечивать поддержку большинства за пределами их внутреннего круга. В XX веке были созданы эффективные политические технологии и каналы прокачки идеологем с целью создания мнимого или реального консенсуса, в том числе, через форумы или «площадки мнений»): медиа, институт анализа общественного мнения, университеты, школы, и т.д;

- поддержание (reinforcing) политкорректных табу и правил, включая систему наказаний, протестов, бойкотов, индивидуального террора и т.д.;
- внедрение идеологии политкорректности в политику (внешнюю и внутреннюю) и социальную практику: захват социальных институтов с помощью законов, правил и регулятивов, контролирующих государственные программы, индустрий воспитания детей и развлечений, образовательных институтов и органов власти на всех уровнях.

Вопрос об оппозиции идеологии политкорректности, противостояния ее тотальному контролю общественного сознания, как я отметила ранее, остался за пределами книги Ионина, между тем она, оппозиция, также есть составная часть этого феномена. И уже упомянуто выше, что книга Ионина содержит многочисленные примеры торжества политкорректности, но ни одного примера противостояния или победы над этим явлением. Описанные автором механизмы формирования общественного мнения не включают никаких контрамеханизмов, которые изначально заложены в природе демократического общества. Между тем литература на эту тему обширна. Кроме названных мною выше книжных публикаций существует много материалов на эту тему в новых медиа: интернетных публикациях, форумах, блогах. Как могло случиться, что автор не заметил этой составляющей общественного дискурса? Может быть потому, что он изначально исходил из тезиса «победившей политкорректности»? Такая авторская установка неизбежно приводит к тому, что предложенная в книге интерпретация феномена политкорректности сама, в определенной степени, политкорректна, даже если автор не имел этого в виду, а кроме того, как я старалась показать, она неполна и внутренне протоворечива. 


\section{Библиография}

1. Ионин Л. Г. Политкорректность: дивный новый мир. М.: Ад Маргинем, 2012.

2. Ионин Л.Г. Апдейт консерватизма. М.: Изд. Дом Гос. ун-та - Высшая школа экономики, 2010.

3. Розин В.М. Становление и особенности социальных институтов: Культурноисторический и методологический анализ. М: Либриком, 2013.

4. Cochin A. Organizing the Revolution. Rockford (IL): Chronicles press, 2007.

5. Hughes G. Political correctness: A history of semantics and culture. Chichester (UK): Wiley-Blackwell, 2010.

6. Taine $\mathrm{H}$. The Origins of Contemporary France. Glouster, Mass: Henry Holt \& CO, 1962.

\section{References (transliterated)}

1. Ionin L. G. Politkorrektnost': divnyi novyi mir. M.: Ad Marginem, 2012.

2. Ionin L. G. Apdeit konservatizma. M.: Izd. Dom Gos. un-ta - Vysshaya shkola ekonomiki, 2010.

3. Rozin V. M. Stanovlenie i osobennosti sotsial'nykh institutov: Kul'turno-istoricheskii i metodologicheskii analiz. M: Librikom, 2013.

4. Cochin A. Organizing the Revolution. Rockford (IL): Chronicles press, 2007.

5. Hughes G. Political correctness: A history of semantics and culture. Chichester (UK): Wiley-Blackwell, 2010.

6. Taine H. The Origins of Contemporary France. Glouster, Mass: Henry Holt \& CO, 1962. 